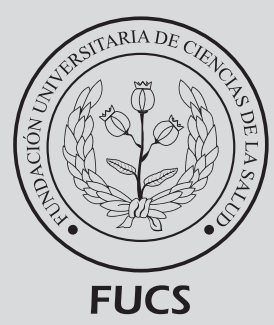

\title{
Afinidad entre las pruebas PCR y antígeno y su positividad Para COVID-19 en Colombia
}

\section{Affinity between the PCR and antigen tests and their positivity for COVID-19 in Colombia}

a Ingeniero. Magister en Gestión de la Tecnología Educativa, Especialista en Administración de la Informática Educativa.

Docente de matemáticas e Investigador, Secretaría de Educación de Soacha, Cundinamarca.

\section{R E S U M EN}

Introducción: : El síndrome respiratorio agudo severo por coronavirus (SARS-CoV-2), el virus que origina la enfermedad 2019 (COVID-19) se ha diseminado con rapidez por todo el mundo desde que surgió en Wuhan, China, a finales de 2019. Objetivo: describir el comportamiento de positividad de muestras tomadas para SARS-CoV-2. Metodología: esta investigación se centró en las muestras de PCR y antígeno procesadas para COVID-19, con la información proveniente del Instituto Nacional de Salud en el periodo comprendido entre el 1 de enero a 31 de marzo 2021. Resultados: para la prueba de PCR en cada uno de los meses de enero a marzo 2021 en Colombia, se detalló que los días con mayor porcentaje de casos positivos fueron 12 de enero 56,3\%, 7 de enero 44,9\%, 6 de enero 45,1\%, 5 de enero 43,7\%, 2 de enero 38,1\%, 24 de marzo $35,2 \%, y 26$ de marzo con 31,3\%. Para la prueba de antígeno en cada uno de los meses de enero a marzo 2021 en Colombia, se anota que los días con mayor porcentaje de casos positivos fueron 11 de enero 32,7\%, 4 de enero 31,0\%, 15 de enero 28,9\%, 18 de enero 22,4\%, 22 de marzo 21,1\%, 28 de marzo 20,7\%, y 17 de febrero 20,1\%. Conclusión: hay que continuar la búsqueda activa de contagiados a través de la práctica de mayor número de pruebas de PCR, antígeno viral y molecular, la última con un alto nivel de precisión por parte de las EPS, y que a su vez aceleren el proceso de entrega de resultados.

Palabras clave: COVID-19, SARS-CoV-2, pandemia, pruebas diagnósticas.

(C) 2021 Fundación Universitaria de Ciencias de la Salud - FUCS. Este es un artículo Open Access bajo la licencia CC BY-NC-ND (http://creativecommons.org/licenses/by-nc-nd/4.0/).

\section{INFORMACIÓN DEL ARTÍCULO}

Historia del artículo:

Fecha recibido: abril 7 de 2021

Fecha aceptado: abril 28 de 2021

\footnotetext{
Autor para correspondencia.

Jorge Enrique Díaz Pinzón jediazp@unal.edu.co
}

DOI

10.31260/RepertMedCir.01217372.1192 


\section{A BSTRACT}

Introduction: Severe acute respiratory syndrome coronavirus 2 (SARS-CoV-2), the virus that causes coronavirus disease 2019 (COVID-19) has spread rapidly around the world since it emerged in Wuhan, China, in late 2019. Objective: to describe the positivity rates of samples tested for SARS-CoV-2. Methodology: the research focused on PCR and antigen tests processed for COVID-19, using the information released by the National Institute of Health between January 1 and March 312021. Results: the highest positivity rate for PCR testing for each month between January to March 2021 in Colombia was found on the following days: January 12: 56.3\%, January 7: 44.9\%, January 6: $45.1 \%$, January 5: 43.7\%, January 2: $38.1 \%$, March 24: $35.2 \%$ and March 26: $(31.3 \%$. The days with the highest percentage of positive cases found by antigen testing for each month from January to March 2021 in Colombia, were January 11: 32.7\%, January 4: 31.0\%, January 15: 28.9\%, January 18: 22.4\%, March 22: 21.1\%, March 28: 20.7\% and February 17: 20.1\%. Conclusion: an active search of infected people must be continued through the practice of a greater number of PCR and viral antigen and molecular tests. The latter has been reported by the EPS to show very high accuracy, which accelerates the result delivery process.

Key words: COVID-19, SARS-CoV-2, pandemic, diagnostic tests.

(C) 2021 Fundación Universitaria de Ciencias de la Salud - FUCS This is an open access article under the CC BY-NC-ND license (http://creativecommons.org/licenses/by-nc-nd/4.0/).

\section{INTRODUCCIÓN}

El síndrome respiratorio agudo severo por coronavirus (SARS-CoV-2), el virus que origina la enfermedad 2019 (COVID-19), se ha extendido velozmente por el mundo desde que surgió en Wuhan, China, a fines de 2019. ${ }^{1} \mathrm{La}$ comprensión actual de COVID-19 procede en gran parte de la vigilancia de la enfermedad y los estudios epidemiológicos elaborados en las primeras fases de la pandemia en China ${ }^{2,3}$ y los países de altos ingresos de Europa ${ }^{4,5}$ y América del Norte. $^{6-8}$

La pandemia mundial por COVID-19 ha causado más de 100 millones de casos confirmados y más de 2 millones de víctimas mortales desde diciembre 2019. Como el virus de ARN, SARS-CoV-2 tiene una mutación relativamente alta, da como resultado una variedad de mutaciones dentro de su genoma. En el último año más de 20.000 de ellas y algunas inserciones/ eliminaciones han sido detectadas en cepas de SARS-CoV-2. ${ }^{9}$ Se han reconocido casos en todos los continentes del mundo y el 6 de marzo 2020 se confirmó el primero en Colombia. La infección se evidencia cuando una persona enferma tose o estornuda y expulsa partículas del virus que entran en contacto con otras personas. ${ }^{10}$

Las pruebas basadas en antígenos para el SARS-CoV-2, el virus que causa la enfermedad por coronavirus 2019 (COVID-19), son económicas y pueden arrojar resultados en 15 minutos. " "La prueba confirmatoria por laboratorio para COVID-19 es la detección de ácidos nucleicos basada en la identificación d el á cido n ucleico ( ARN) d el SARSCoV-2 mediante ensayos de RT-PCR. Este tipo de examen tiene alta sensibilidad y especificidad y es la indicada por la OMS y OPS para realizar la confirmación diagnóstica de COVID-19". ${ }^{12}$

"La prueba de detección de antígeno es un método de diagnóstico alternativo para SARS-CoV-2 (COVID-19).
De acuerdo con la literatura científica es un poco menos sensible que la RT-PCR, por lo regular es más rápida y fácil de implementar en los laboratorios clínicos (en menos de 30 minutos se obtiene el resultado). Se ha demostrado alta sensibilidad y buena especificidad en las validaciones secundarias realizadas en el país a las pruebas evaluadas en la infección temprana (hasta 11 días después del inicio de síntomas). La muestra que se requiere para estas pruebas es a través de hisopado nasofaríngeo". ${ }^{13}$

El objetivo de esta investigación es mostrar si existe diferencia entre el promedio de casos positivos para la prueba PCR para COVID-19 y el promedio de casos positivos para la prueba de antígeno para COVID-19 en el periodo comprendido entre el 1 de enero al 31 de marzo 2021.

\section{METODOLOGÍA}

El trabajo de investigación es de tipo experimental: aquella que permite mayor seguridad al establecer relaciones de causa a efecto presenta una visión general y aproximada del objeto de estudio, además de contar con una investigación cuyo diseño establece un método experimental habitual del conjunto de las normas científicas, Monje (2011) citado por Díaz. ${ }^{14}$ Shuttleworth citado por Díaz ${ }^{15,16}$ menciona que como norma estos experimentos se conocen como ciencia verdadera y manejan medios matemáticos y estadísticos cotidianos para evaluar los resultados de modo concluyente. Todos los experimentos cuantitativos utilizan un formato estándar con algunas pequeñas diferencias interdisciplinarias para generar una hipótesis que será probada o desmentida. Esta hipótesis debe ser demostrable por medios matemáticos 
y estadísticos y constituye la base alrededor de la cual se diseña todo el experimento.

\section{POBLACIÓN}

La información se obtuvo de la página web del Instituto Nacional de Salud ${ }^{17}$ de los informes diarios de las pruebas para PCR y antígeno y su positividad entre el 1 de enero al 31 de marzo 2021.

\section{RES ULTADOS}

\section{Formulación de hipótesis}

La hipótesis del presente trabajo de investigación se diseña como una relación causal y se enuncia de la siguiente forma: a) hipótesis alterna (Ha): existen diferencias significativas entre el promedio o la media de casos positivos para la prueba PCR y antígeno para COVID-19; b) hipótesis nula (Ho): no existen diferencias significativas entre el promedio o la media de casos positivos para la prueba PCR y antígeno para COVID-19. Nivel de significancia: $=5 \%=0,5$.

Tabla 1. ANOVA-Positivos pruebas PCR y antígeno.

\begin{tabular}{|llllll|}
\hline & Suma de cuadrados & gl & Media cuadrática & F & Sig. \\
\hline Entre grupos & 375506446,050 & 1 & 375506446,050 & $35,116,000$ \\
\hline Dentro de grupos & 1903388205,611 & 178 & 10693192,166 & \\
\hline Total & 2278894651,661 & 179 & & \\
\hline Fuente: el autor & & & & \\
\hline
\end{tabular}

Toma de decisión: sí el p- valor < a es aceptar Ha, entonces rechazamos la hipótesis nula y nos quedamos con la hipótesis del investigador (Ha). En la tabla 1 se aprecia el p-valor de las pruebas, para la variable casos positivos de las muestras de PCR y antígeno que es de 0,000, es menor a $\alpha=0.05$, de esta manera se acepta Ha, es decir la prueba de análisis de varianza que nos indica las diferencias significativas entre las pruebas positivas para pruebas PCR y antígeno para COVID-19 en Colombia durante el período comprendido entre el 1 de enero al 31 de marzo 2021.

En la figura 1 se aprecian los datos de la positividad en porcentaje (\%), para la prueba de PCR en cada uno de los meses de enero a marzo 2021 en Colombia, se detalla que los días con mayor porcentaje de casos positivos fueron 12 de enero $56,3 \%, 7$ de enero $44,9 \%, 6$ de enero $45,1 \%, 5$ de enero 43,7\%, 2 de enero 38,1\%, 24 de marzo 35,2\%, y 26 de marzo $31,3 \%$. En la figura 2 se aprecian los datos de la positividad en porcentaje (\%)para la prueba de antígeno en cada uno de los meses de enero a marzo 2021 en Colombia, se detalla que los días con mayor porcentaje de casos positivos fueron 11 de enero $32,7 \%, 4$ de enero $31,0 \%, 15$ de enero $28,9 \%, 18$ de enero $22,4 \%, 22$ de marzo $21,1 \%, 28$ de marzo $20,7 \%$, y 17 de febrero $20,1 \%$.

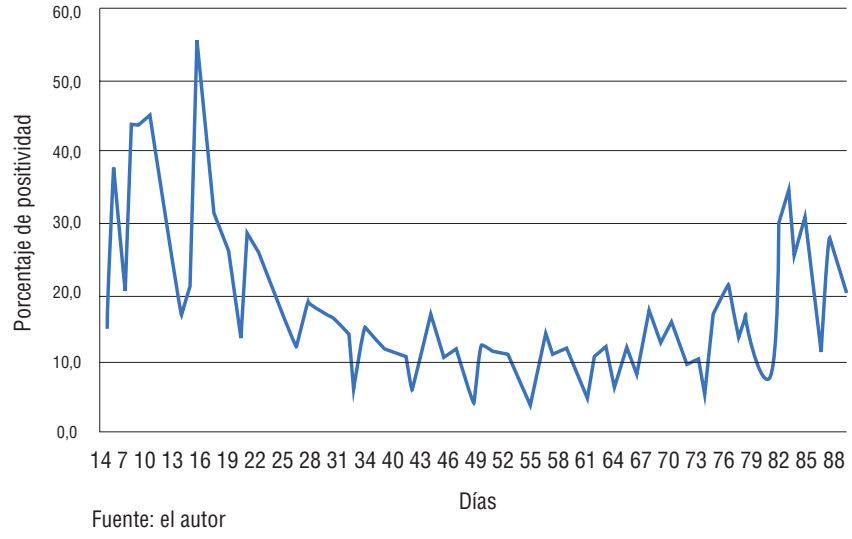

Figura 1. Positividad de muestras PCR en porcentaje

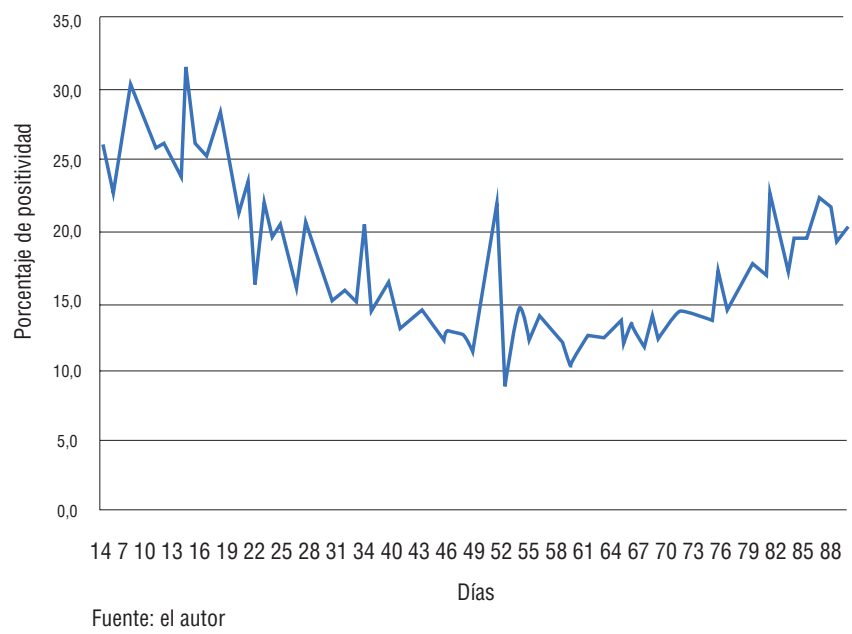

Figura 2. Positividad de muestras para antígeno en porcentaje.

\section{Diagrama de caja}

La figura 3 describe los detalles de un diagrama de caja para las muestras PCR y antígeno que involucra la mediana, los percentiles 25 y 75 (en realidad son las bisagras de Tukey) y una serie de valores (atípicos, extremos). En nuestro caso para las muestras PCR el percentil 25 es igual a 24.679, el 50 a 32.040 y el percentil 75 a 39.930,25, con un valor mínimo de 15.430 y un máximo de 53.065 pruebas de PCR. Para el caso de las pruebas con antígeno, el percentil 25 es igual a $13.078,25$, el 50 a 19.198 y el percentil 75 a 23.392,75, con un valor mínimo de 6.249, y un máximo de 47.072.

La figura 4 describe los detalles de un diagrama de caja para las muestras positivas de PCR y antígeno que involucra la mediana, los percentiles 25 y 75 (en realidad son las bisagras de Tukey) y una serie de valores (atípicos, extremos).

En nuestro caso para las muestras positivas de PCR, el percentil 25 es igual a $2.957,75$, el 50 a $5.907,08$ y el percentil 75 a 7.626,25, con un valor mínimo de 1.059, y un máximo de 15.757. Para el caso de los positivos para pruebas con antígeno, el percentil 25 es igual a 1.424,75, el 50 a 3.018,38 y el percentil 75 a $3.897,75$, con un valor mínimo de 473 , y un máximo de 12.990 . 


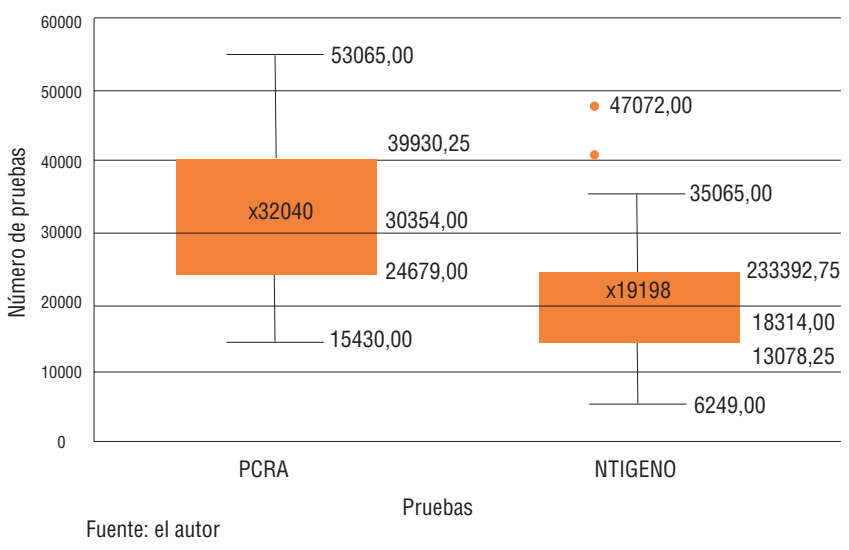

Figura 3. Diagrama de caja para pruebas PCR y antígeno.

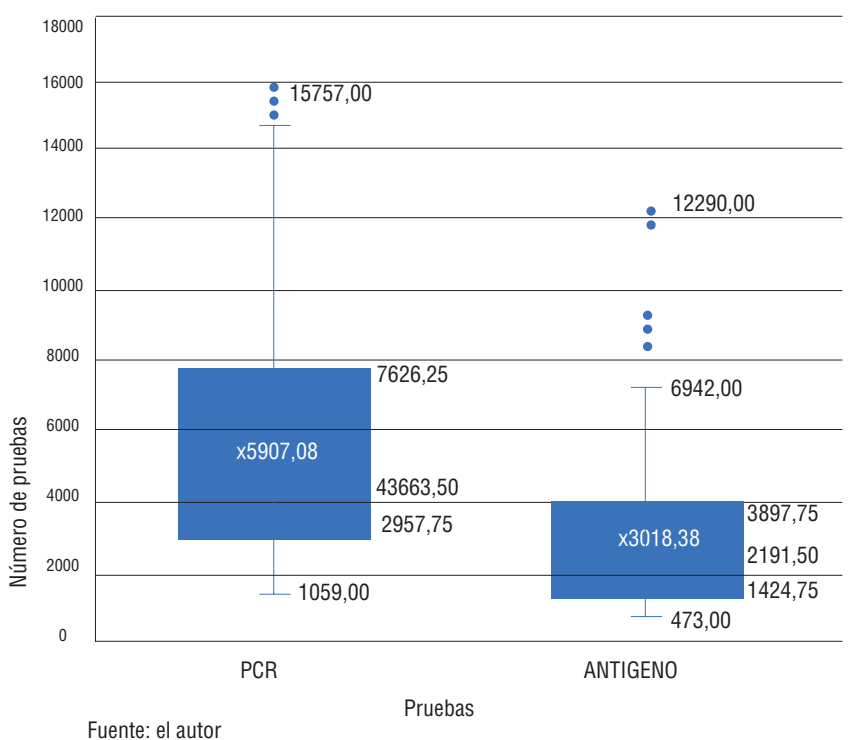

Figura 4. Diagrama de caja para positividad de muestras para PCR y antígeno

\section{CONCLUSIONES}

A partir del análisis estadístico de los datos aplicando el análisis de varianza se puede observar que hay evidencia para rechazar la hipótesis nula; por lo tanto, las medias son estadísticamente diferentes. Es decir, que se aprecian diferencias representativas entre la media de casos positivos de pruebas PCR con el promedio de los casos positivos de la prueba con antígeno.

Para la prueba de PCR en cada uno de los meses de enero a marzo 2021 en Colombia, se detalló que los días con mayor porcentaje de casos positivos fueron 12 de enero 56,3\%, 7 de enero 44,9\%, 6 de enero $45,1 \%, 5$ de enero $43,7 \%, 2$ de enero $38,1 \%, 24$ de marzo 35,2\%, y el 26 de marzo $31,3 \%$. para la prueba de antígeno, para cada uno de los meses de enero a marzo 2021 en Colombia, se detalla que los días con mayor porcentaje de casos positivos fueron 11 de enero
$32,7 \%, 4$ de enero $31,0 \%, 15$ de enero $28,9 \%, 18$ de enero $22,4 \%, 22$ de marzo 21,1\%, 28 de marzo 20,7\%, y 17 de febrero $20,1 \%$.

Hay que continuar la búsqueda activa de personas contagiadas a través de la práctica de mayor número de pruebas de PCR, antígeno viral y molecular, esta última con un alto nivel de precisión por parte de las EPS y que a su vez apresuren el proceso de entrega de resultados a las personas, para que de esta forma se pueda tener un dato existente de rigor de la transmisión y el contagio de la enfermedad $\mathrm{y}$ poder realizar las respectivas medidas sanitarias y toma de decisiones terapéuticas amparadas para la ejecución de protocolos clínicos de actuación rápida. ${ }^{18}$

\section{REFEREN CIAS}

1. Li Q, Guan X, Wu P, Wang X, Zhou L, Tong Y, et al. Early Transmission Dynamics in Wuhan, China, of Novel Coronavirus-Infected Pneumonia. N Engl J Med. 2020;382(13):1199-1207. doi: 10.1056/NEJMoa2001316

2. Zhou F, Yu T, Du R, Fan G, Liu Y, Liu, Z. Clinical course and risk factors for mortality of adult inpatients with COVID-19 in Wuhan, China: a retrospective cohort study. Lancet. 2020;395(10229):10541062. doi: 10.1016/S0140-6736(20)30566-3

3. Hoffmann, M, Kleine-Weber $\mathrm{H}$, Schroeder $\mathrm{S}$, Krüger $\mathrm{N}$, Herrler $\mathrm{T}$, et al. SARS-CoV-2 Cell Entry Depends on ACE2 and TMPRSS2 and Is Blocked by a Clinically Proven Protease Inhibitor. Cell. 2020;181(2):271-280.e8. doi: 10.1016/j.cell.2020.02.052

4. Grasselli G, Zangrillo A, Zanella A, Antonelli M, Cabrini L, et al. Baseline Characteristics and Outcomes of 1591 Patients Infected With SARS-CoV-2 Admitted to ICUs of the Lombardy Region, Italy. JAMA. 2020;323(16):1574-1581. doi: 10.1001/jama.2020.5394

5. Docherty A, Harrison E, Verde C, Hardwick S, Pius R, Norman L, et al. Features of 20133 UK patients in hospital with covid-19 using the ISARIC WHO Clinical Characterisation Protocol: prospective observational cohort study. BMJ. 2020;369:m1985. doi: 10.1136/ bmj.m1985

6. Richardson S, Hirsch J, Narasimhan S, Crawford J, McGinn T, Davidson K, et al. Presenting Characteristics, Comorbidities, and Outcomes Among 5700 Patients Hospitalized With COVID-19 in the New York City Area. JAMA. 2020 May 26;323(20):2052-2059. doi: 10.1001/ jama.2020.6775

7. Petrilli C, Jones S, Yang J, Rajagopalan H, O'Donnell L, Chernyak $\mathrm{Y}$, Tobin $\mathrm{K}$, et al. Factors associated with hospital admission and critical illness among 5279 people with coronavirus disease 2019 in New York City: prospective cohort study. BMJ. 2020;369:ml966. doi: 10.1136/ bmj.m1966

8. Lewnard J, Liu V, Jackson M, Schmidt M, Jewell B, Flores J, et al. Incidence, clinical outcomes, and transmission dynamics of severe coronavirus disease 2019 in California and Washington: prospective cohort study. BMJ. 2020;369:m1923. doi: 10.1136/bmj.m1923

9. Wu A, Wang L, Yang Z, Ji S, Xa S, Cao Y, Jing Meng J, Ding X, Gold S, Jiang T, Cheng G. One year of SARS-CoV-2 evolution. Cell Host Microbe. 2021 Apr 14;29(4):503-507. doi: 10.1016/j.chom.2021.02.017 
10. Díaz-Pinzón JE. Uso de modelo predictivo para la dinámica de transmisión del COVID-19 en Colombia. Repert Med Cir. 2020;29(Núm. Supl.1):34-44. doi:10.31260/ RepertMedCir.01217372.1056

11. National Center for Immunization, Respiratory Diseases (NCIRD), Division of Viral Diseases. Interim Guidance for Antigen Testing for SARS-CoV-2 [Internet]. United State: Centers for Diseases Control and Prevention; 2020 [cited 2021 marzo 19]; Available from: https://www.cdc.gov/coronavirus/2019-ncov/lab/resources/ antigen-tests-guidelines.html.

12. Ministerio de Salud y Protección Social. Lineamientos para el uso de pruebas en el laboratorio de salud pública (ISP) en el marco de la emergencia sanitaria por (covid-19) en Colombia. Colombia: Ministerio de Salud y Protección Social; 2020. p. 29.

13. Ministerio de Salud y Protección Social. Lineamientos para el uso de pruebas moleculares RT-PCR, pruebas de antígeno y pruebas serológicas para SARS-CoV-2 (COVID-19) en Colombia. Colombia: Ministerio de Salud y Protección Social; 2020. p.34.
14. Díaz Pinzón JE. Soporte técnico de simulación Phet en la enseñanza y aprendizaje de fracciones equivalentes. Rev Invest Univ Quindío (Col.). 2016;28(2):31-41

15. Díaz-Pinzón JE. Correlación y regresión lineal de la evaluación tiempo y puntaje con recurso interactivo flash. INNOVA Research Journal. 2017;2(10):1-8. doi: 10.33890/innova. v2.n10.2017

16. Díaz-Pinzón JE. Estudio de los resultados del contagio por COVID-19 a nivel mundial. Repert Med Cir. 2020;29(Núm. Supl.1):65-71. doi: 10.31260/RepertMedCir.01217372.1089

17. Instituto Nacional de Salud. Coronavirus (COVID-2019) en Colombia [Internet]. Bogotá: Instituto Nacional de Salud; 2020 [citado 2021 marzo 19]; Recuperado de: https:/www.ins.gov.co/ Noticias/Paginas/Coronavirus.aspx

18. Díaz-Pinzón JE. Positividad y proporción para muestras por COVID-19 en Colombia. Repert Med Cir. 2020;29(Núm. Supl.1):127-130. doi: 10.31260/RepertMedCir.01217372.1134 